Research Article

\title{
Mechanical Characteristics of Coal Samples under Triaxial Unloading Pressure with Different Test Paths
}

\author{
Yang Zhang, ${ }^{1}$ Yongjie Yang $\mathbb{D},{ }^{1}$ and Depeng $\mathrm{Ma} \mathbb{D}^{2}$ \\ ${ }^{1}$ State Key Laboratory of Mining Disaster Prevention and Control Co-Founded by Shandong Province and the Ministry of \\ Science and Technology, Shandong University of Science and Technology, Qingdao 266590, China \\ ${ }^{2}$ College of Water Conservancy and Civil Engineering, Shandong Agricultural University, Tai'an 271018, China
}

Correspondence should be addressed to Yongjie Yang; yyj.6125@163.com

Received 25 May 2020; Revised 10 July 2020; Accepted 13 July 2020; Published 10 August 2020

Academic Editor: Xuesheng Liu

Copyright (c) 2020 Yang Zhang et al. This is an open access article distributed under the Creative Commons Attribution License, which permits unrestricted use, distribution, and reproduction in any medium, provided the original work is properly cited.

In order to understand the influence of unloading path on the mechanical properties of coal, triaxial unloading confining pressure tests with different initial confining pressure and different unloading rate were carried out. The test results show that the triaxial unloading strength of coal samples under different test conditions is lower than conventional triaxial tests, but the brittleness characteristics are more obvious. This result indicates that the coal samples are easily damaged under unloading conditions. In the axial loading stage of the confinement unloading tests, the axial strain plays a leading role. However, during the confining pressure unloading stage, the circumferential deformation is large, which is the main deformation in this stage. Higher unloading rates of confining pressure are associated with shorter times between the peak stress position and sample complete failure. This shows that samples are more easily destroyed under higher unloading rates and the samples are more difficultly destroyed under lower unloading rates. In addition, with increasing unloading rate, the peak principal stress difference and confining pressure at failure decrease gradually, whereas the confining pressure difference at failure increases gradually. Compared with conventional triaxial compression tests, the cohesion of coal is reduced and the internal friction angle is increased under the condition of triaxial unloading test.

\section{Introduction}

During excavation of chambers in hydropower projects, mining of deep ore bodies, and other underground projects, frequent disasters caused by high stress unloading, such as rock bursts and gangs, severely restrict the smooth construction of the project. Correctly understanding the rock deformation and failure laws and mechanical characteristics under unloading conditions are the prerequisites and foundations for preventing such disasters. For this reason, Ha Qiuling carried out a lot of hard rock unloading mechanical tests research work and achieved many beneficial results [1-5]. When carrying out the unloading test, the loading stress level at the early stage of unloading is very important. The higher this stress level is, the more microcracks are generated inside the rock at the early stage of unloading. And the interaction between microcracks is also more significant, which means that the damage of the rock in the early stage of unloading is higher. This difference in internal structure and damage degree will directly affect the deformation and failure characteristics of the rock during unloading [5-7]. Unloading initial confining pressure is one of the important controlling factors for rock unloading mechanical characteristics. At present, when conducting unloading tests, researchers generally require that the stress level is higher than the uniaxial compression strength, slightly higher than the triaxial compression ratio limit [8-11], and about $70 \%$ to $80 \%$ of the triaxial compression strength. This setting can meet the requirements of destruction during unloading [12-15]. Therefore, it is necessary and important to design a reasonable test plan for the influence of unloading mechanical characteristics.

For deep engineering, the rock near the excavation face has experienced a complex evolution process of stress paths 
for loading and unloading, which controls the failure mode and deformation law of the rock under high stress [16-18]. Therefore, it is also important to research the control effect of the stress path. The unloading rate has an obvious effect on the mechanical properties of rock unloading, but the effect mechanism is still unclear. This brings great obstacles to correctly understand the rock unloading failure mechanism [19]. Theoretical achievements of unloading rock mechanics indicate that there are obvious differences in mechanical properties of rock under two different mechanical states of unloading and loading. And it is suggested to use the loading and unloading theory for engineering analysis and research according to the mechanical state of the engineering structure $[20,21]$. However, there are many factors that affect the mechanical properties of rock unloading. In terms of anisotropy, size effect, tensile shear fracture, and rheological properties of rock, theory of unloading rock mechanics has been conducting in-depth research on the effects of unloading mechanical characteristics of rock $[22,23]$. In addition to the above influencing factors, the unloading rate also has a significant effect on the mechanical properties of the rock unloading. For example, rock bursts under high geostress conditions are closely related to the unloading rate. During construction, the risk of rock bursts is often reduced by slowing the excavation speed and reducing the excavation footage. The essence is to adjust the unloading rate of surrounding rock caused by excavation [24-26]. However, the mechanism by which the unloading rate affects the mechanical properties of the rock is unclear, especially in the process of coal mining. Therefore, the influence of unloading rate on the mechanical properties of rock (coal) is still one of the important topics in the study of unloading rock mass mechanics.

In view of the importance of correct understanding of the mechanical properties of rock unloading and the importance of guiding significance for the prevention and control of mining engineering disasters, based on the triaxial unloading confining pressure tests of coal with different unloading rates and different initial unloading confining pressures, this paper studies the unloading strength characteristics and deformation laws of coal rocks under different unloading paths and reveals the control of unloading paths' effect. Combined with the actual mining engineering, this paper discusses the engineering guiding significance of unloading test and provides theoretical basis for the prevention and control of unloading damage in mining roadway and working face.

\section{Materials and Methods}

2.1. Starting Material. Coal samples were collected from the No. 16 coal seam in the Yangcun coal mine. This seam is located in the lower part of Taiyuan coal mine and is 2.45-14.40 m higher than the No. 17 seam with an average difference of $6.79 \mathrm{~m}$. The coal seam structure is simple and some segments have 1-2 layers of rock. The rock lithology is carbonaceous mudstone and pyrite with a thickness of $0.02-0.44 \mathrm{~m}$. Large blocks of coal without joints were selected from the underground coal mines, packaged, and transported to the laboratory for coring. According to the engineering rock test method standard (GB/T50266-99), the coal was processed into standard cylindrical specimens of $50 \times 100 \mathrm{~mm}$ (diameter $\times$ height), as shown in Figure 1 . After sample processing and molding, the surface of both sample ends was carefully polished to a smoothness of less than $0.02 \mathrm{~mm}$. To reduce the influence of sample dispersion, sound wave tests were performed and samples with a large dispersion of wave velocity were excluded. Samples with wave velocities ranging from 1900 to $2000 \mathrm{~m} / \mathrm{s}$ were selected for testing.

2.2. Experimental Procedure. Triaxial compression tests and triaxial confinement unloading tests were performed using a MTS815.02 electrohydraulic servo rock mechanics test system. The system meets test requirements under various complex paths. The specific test scheme is designed as follows.

2.2.1. Conventional Triaxial Compression Tests. There are two stages in the test path design. [1] The first is increasing confining pressure by means of stress control. The confining pressure is applied gradually to the set value according to the hydrostatic pressure conditions of 4,7 , or $10 \mathrm{MPa}$ [2]. Confining pressure is held constant and displacement control is adopted to increase axial compression until sample failure using a loading rate of axial displacement of $0.002 \mathrm{~mm} / \mathrm{s}$.

2.2.2. Triaxial Confinement Unloading Tests. The lateral stress of coal (equivalent to confining pressure in the tests) in the working face decreases gradually with advancing underground mining working face, whereas the influence of mining overburden movement leads to a gradual increase of the advance abutment pressure (which corresponds to axial stress in the tests). Mining of a working face is a process of decreasing confining pressure and increasing axial pressure of the coal and surrounding rock. To allow the test path to most realistically simulate actual engineering situations, unloading paths of increasing axial pressure and unloading confining pressure are adopted in the tests. The breaking time is the shortest and most dangerous under this path.

Because rock stress varies with burial depth and the rate of lateral rock stress reduction varies with advancing working face speed, we performed triaxial confinement unloading tests on specimens under different initial confining pressures and confining pressure unloading rates.

The experiments are divided into three stages [1]. Confining pressure is increased. The confining pressure $\sigma_{3}$ is gradually applied to a predetermined value according to the hydrostatic pressure conditions $(4,7$, and $10 \mathrm{MPa})$ [2]. The confining pressure $\sigma_{3}$ is held fixed and stress control is used to increase the axial compression $\sigma_{1}$ to a stress state prior to rock breakdown ( $80 \%$ of the peak stress of conventional triaxial compression) [3]. The stress control mode is changed to displacement control mode and continues to increase $\sigma_{1}$. At the same time, the confining pressure $\sigma_{1}$ is released at a 


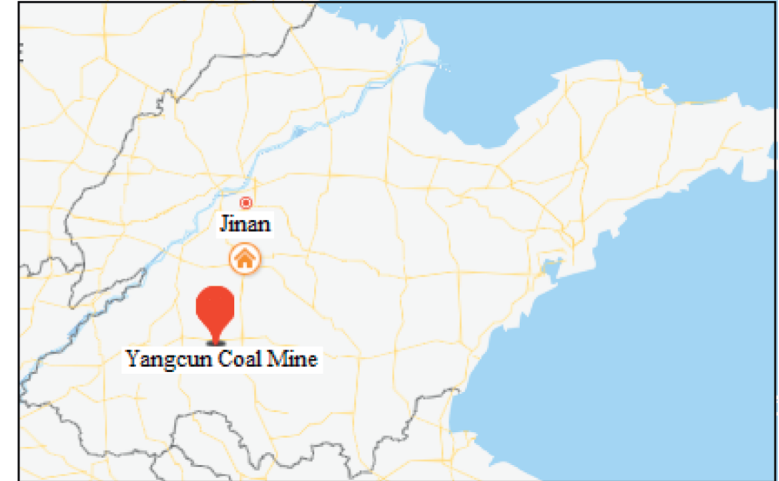

(a)

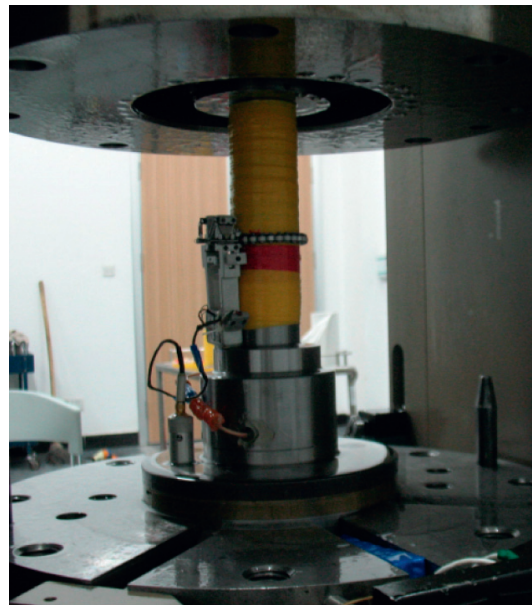

(c)

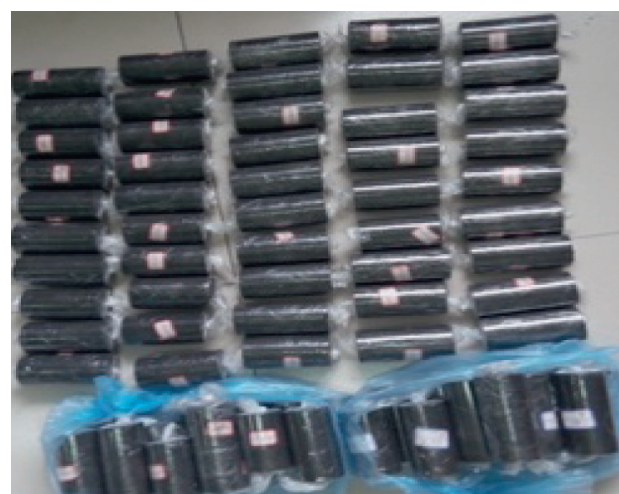

(b)

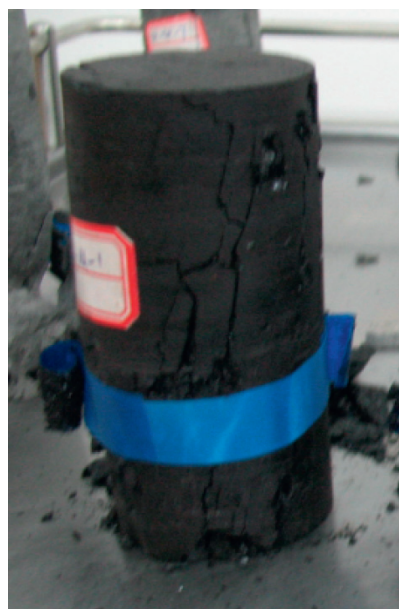

(d)

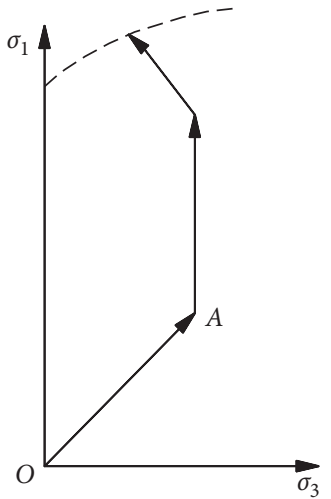

(e)

Figure 1: Testing apparatus and rock samples after testing.

given rate $(0.02,0.05$, or $0.08 \mathrm{MPa} / \mathrm{s})$ until the sample is destroyed. Unloading confining pressure is stopped immediately after destruction and axial displacement continues to load to the sample residual strength.

\section{Coal Deformation and Strength \\ Characteristics Analysis under Conventional Triaxial Compression}

Conventional triaxial compression tests under different confining pressures were carried out and the obtained stressstrain curves are shown in Figures 2 and 3. The stress-strain curves of different samples under the conventional triaxial tests are essentially the same. The sample fracture process can be roughly divided into five stages: a compaction stage $(\mathrm{OA})$, linear elastic stage $(\mathrm{AB})$, fracture expansion and expansion stage (BD), unstable macrofracture stage (DE), and a residual plastic stage $(\mathrm{EF})$.

Table 1 lists the coal test data from conventional triaxial compression tests. The deformation and failure characteristics of the coal samples are as follows.

(1) The elastic modulus, Poisson's ratio, and peak stress increase with increasing confining pressure. The results show that sample deformation and failure are

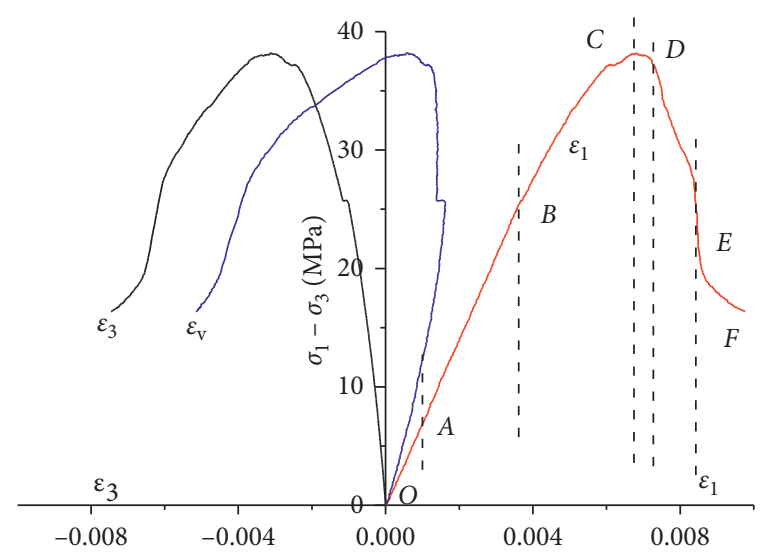

FIGURE 2: Stress-strain curves of coal from triaxial compression tests.

restrained under confining pressure, the bearing capacity increases, and the slope of the straight section of the axial stress-strain curve increases.

(2) Stress at the inflection point of the volumetric strain increases with increasing confining pressure. The ratio of stress to peak stress at the inflection point of volumetric strain under different confining pressures 


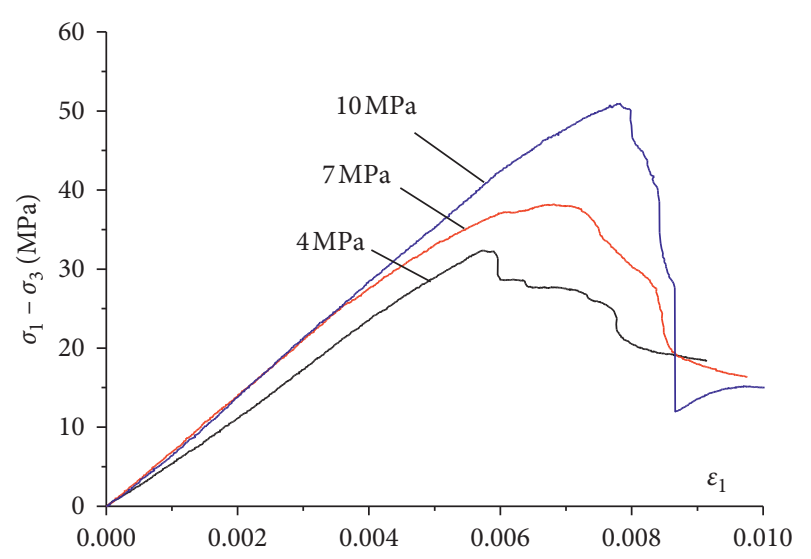

FIGURE 3: Stress-strain curves from triaxial compression tests under different confining pressure conditions.

is mostly $70 \%-80 \%$. With increasing confining pressure, the ratio slightly decreases and the axial strain and circumferential strain at peak stress increase.

\section{Analysis of Triaxial Unloading Deformation and Coal Strength Characteristics}

4.1. Stress-Strain Analysis of Triaxial Unloading of Coal. The coal stress-strain curve of triaxial confining pressure test under different initial confining pressures and confining pressure unloading rate are shown in Figure 4.

The letter C stands for coal and the numbers 4,7 , or 10 represent the different initial confining pressures for unloading (MPa). The numbers of $0.05,0.08$, and so on represent the rate of confining pressure relief $(\mathrm{MPa} / \mathrm{s})$.

The experimental data from the triaxial confinement unloading tests of coal under different initial unloading confining pressure and unloading rates are listed in Table 2.

Figure 4 and Table 2 show that the brittleness of coal and sandstone is more apparent under triaxial confinement unloading than in conventional triaxial compression tests. A brittle sound occurs at failure and the axial strain-stress curve of sandstone shows a sharp downward trend after the peak value.

In Table 2, symbol $\varepsilon_{1}$ represents axial strain, $\varepsilon_{3}$ is circumferential strain, $\varepsilon_{\mathrm{v}}$ is volumetric strain, $\sigma_{3}$ is confining pressure $(\mathrm{MPa}), v_{\sigma 3}$ is the confining pressure unloading rate $(\mathrm{MPa} / \mathrm{s}), \sigma_{1}-\sigma_{3}$ is the peak principal stress difference $(\mathrm{MPa})$, $\sigma_{3}^{\prime}$ is the sample confining pressure at failure (MPa), and $\sigma_{3}-\sigma_{3}^{\prime}$ is the reduction of confining pressure (MPa). With increasing axial compression (during the axial loading stage), the stress-strain curve is nearly linear (during the decompaction stage), the slope of axial strain is smaller than that of circumferential strain, and the increase rate of the circumferential strain is less than that of axial strain, which is similar to results from conventional triaxial compression. At this time, the volume strain is mainly affected by axial strain. Because of the development of joints and cracks in the samples, circumferential deformation is apparent under the confining pressure action.

When the confining pressure is released because of displacement control for axial loading, the axial strain increases at the original speed, whereas the circumferential strain increases significantly. Volumetric and circumferential strains both increase in the same way. The coal samples begin to expand, which indicate that circumferential strain plays a dominant role in the confining pressure relief stage.

With the continued decrease of confining pressure, the load-carrying capacity of the coal begins to decline and dilatancy occurs. The coal sample breaks and loses stability, producing a crisp sound upon failure. In the triaxial confinement unloading tests with decreasing confining pressure, the confining pressure on the sample surface weakens, which makes the degree of failure during the unloading of confining pressure more severe than that during conventional triaxial compression tests.

The strength characteristic curves of each coal sample are shown in Figure 4 under the different test conditions and a confining pressure unloading velocity of $0.02 \mathrm{MPa} / \mathrm{s}$ in the confinement unloading test. Figure 4 and Table 2 show that the strength curves of conventional triaxial compression tests are at the top of the triaxial unloading confining pressure curve. Additionally, the sample strength under triaxial confinement unloading is lower than that in conventional triaxial tests, which indicates that the coal more easily fractures under unloading confining pressure conditions.

4.2. Variation of Elastic Modulus. The variation curve of the elastic modulus of coal in the unloading confining pressure section under different initial confining pressures and unloading rates is shown in Figure 5. Different initial confining pressures affect the elastic modulus when the rate of confining pressure relief is $0.05 \mathrm{MPa} / \mathrm{s}$ and the initial confining pressure of unloading is $10 \mathrm{MPa}$. It should be noted that the elastic modulus described in this paper refers to the secant modulus.

The elastic moduli of samples under unloading confining pressure are essentially the same for different initial confining pressures and unloading rates. In the initial stage of confining pressure relief, the elastic modulus is nearly linear with increasing confining pressure and increases slowly with decreasing confining pressure. However, the degree of increase is sensitive to initial confining pressure and unloading rate. Higher confining pressure unloading rates are associated with higher degrees of modulus increase. When the confining pressure unloading rate is $0.02,0.05,0.08,0.11$, and $0.14 \mathrm{MPa} / \mathrm{s}$, the elastic modulus increases by 145,262 , 276,312 , and $330 \mathrm{MPa}$, respectively, and the growth period lasts longer. For different initial confining pressures of unloading, higher initial confining unloading pressures are associated with higher ranges of the elastic modulus increase. When the initial confining pressure is 4,7 , and $10 \mathrm{MPa}$, the growth rate during the growth stage is 5,40 , and $145 \mathrm{MPa}$, respectively, and the duration of the growth stage also increases. 
TABLe 1: Triaxial compression test results.

\begin{tabular}{lcccccccc}
\hline Lithology & $\begin{array}{c}\text { Confining } \\
\text { pressure } \\
(\mathrm{MPa})\end{array}$ & $\begin{array}{c}\text { Axial stress } \\
\text { difference } \\
(\mathrm{MPa})\end{array}$ & $\begin{array}{c}\text { Damage } \\
\text { stress } \\
(\mathrm{MPa})\end{array}$ & $\begin{array}{c}\text { Inflection } \\
\text { point ratio }\end{array}$ & $\begin{array}{c}\text { Peak circumferential } \\
\text { strain }(\mathrm{mm} / \mathrm{mm})\end{array}$ & $\begin{array}{c}\text { Peak axial } \\
\text { strain } \\
(\mathrm{mm} / \mathrm{mm})\end{array}$ & $\begin{array}{c}\text { Elastic } \\
\text { modulus } \\
(\mathrm{MPa})\end{array}$ & $\begin{array}{c}\text { Poisson } \\
\text { ratio }\end{array}$ \\
\hline \multirow{3}{*}{ Coal } & 4 & 32.22 & 30.12 & $82.81 \%$ & -0.00202 & 0.00588 & 5522 & 0.23 \\
& 7 & 38.07 & 33.21 & $73.22 \%$ & -0.00250 & 0.00689 & 6674 & 0.23 \\
& 10 & 48.87 & - & - & -0.00263 & 0.00781 & 6680 & 0.31 \\
\hline
\end{tabular}

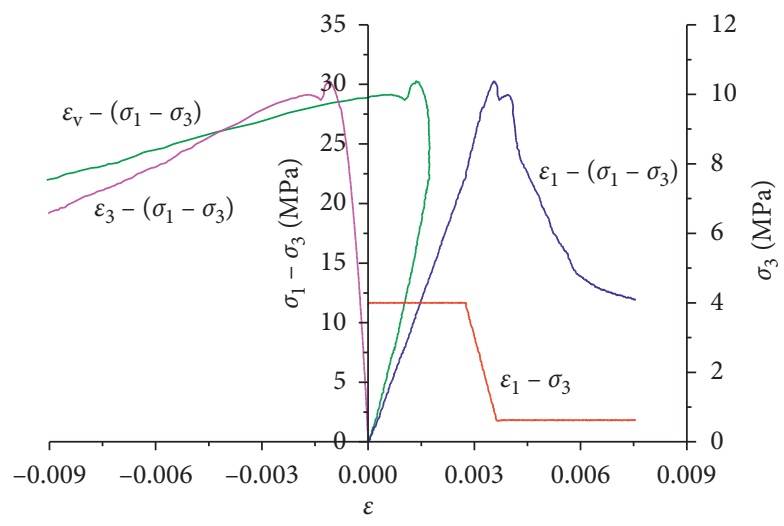

(a)

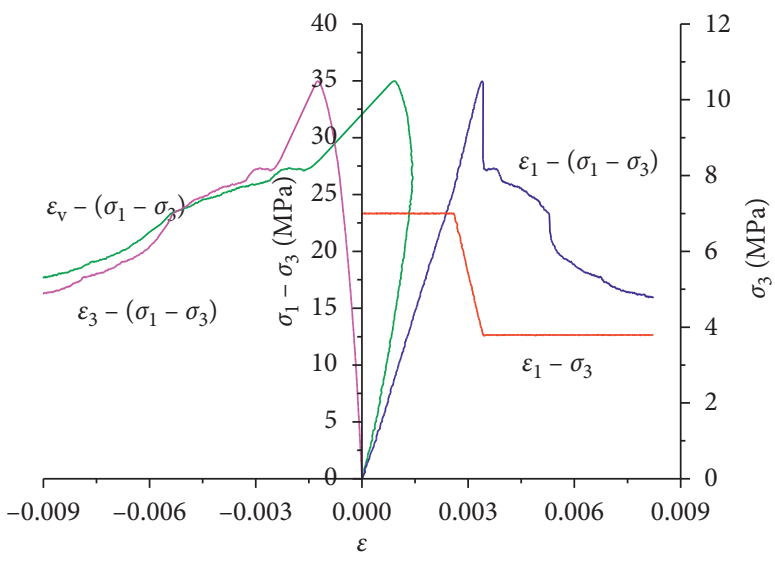

(b)

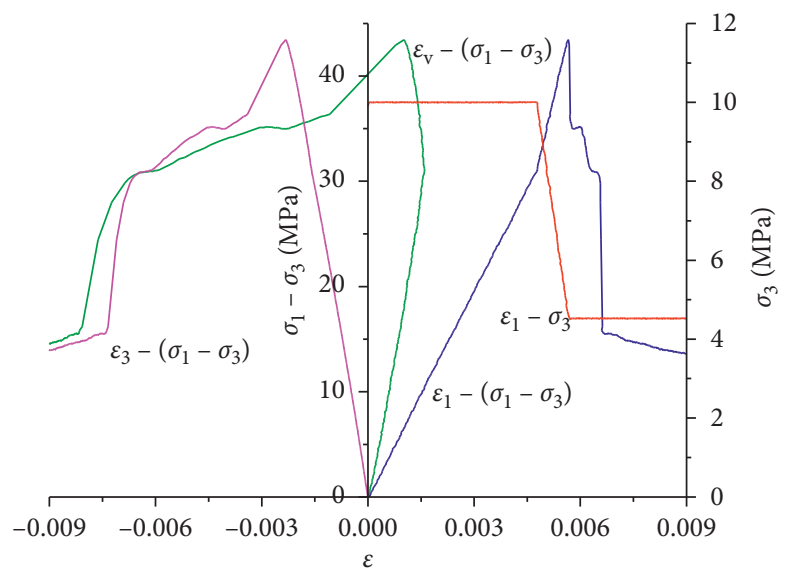

(c)

FIgURE 4: Stress-strain curves of confinement unloading test of coal samples. (a) C-4-0.05, (b) C-7-0.05, and (c) C-10-0.08.

In the middle and late stages of the confinement unloading test, an inflection point appears in the elastic modulus curve, which initially increases gradually and then decreases gradually. The elastic modulus shows a nonlinear relationship with confining pressure.

As confining pressure continues to decrease, the elastic modulus decreases rapidly and the rate of reduction increases and then decreases sharply near the failure stage. With decreasing unloading rate, the elastic modulus first decreases and then increases and no regularity is observed under different initial confining pressure.

4.3. Effect of Confining Pressure Release Rate. The stressstrain curves of coal under different confining pressure unloading rates are shown in Figure 6. The initial unloading confining pressure is $10 \mathrm{MPa}$ with confining pressure unloading rates of $0.02,0.05,0.08,0.11$, and $0.14 \mathrm{MPa} / \mathrm{s}$.

Figure 6 shows that shorter times are required for the coal samples to progress from peak position to failure with increasing confining pressure unloading rate. Under lower rates, samples are less likely to be destroyed.

With increasing confining pressure unloading speed, the peak principal stress difference of coal samples decreases gradually and the range of peak principal stress difference also decreases. This shows that higher unloading rates have a smaller influence on the peak strength variation.

Figure 7 shows that the confining pressure gradually decreases with increasing confining pressure unloading rate. However, the confining pressure difference (i.e., 
TABLe 2: Test data of different initial unloading confining pressure and confining pressure unloading rates.

\begin{tabular}{cccccccccc}
\hline Lithology & $\sigma_{3}(\mathrm{MPa})$ & $\begin{array}{c}v_{\sigma 3} \\
(\mathrm{MPa} / \mathrm{s})\end{array}$ & $\sigma_{1}-\sigma_{3}^{\prime}(\mathrm{MPa})$ & Residual strength $(\mathrm{MPa})$ & $\sigma_{3}^{\prime}(\mathrm{MPa})$ & $\sigma_{3}-\sigma_{3}^{\prime}(\mathrm{MPa})$ & $\begin{array}{c}\varepsilon_{3} \\
(\mathrm{~mm} / \mathrm{mm})\end{array}$ & $\begin{array}{c}\varepsilon_{1} \\
(\mathrm{~mm} / \mathrm{mm})\end{array}$ & $\begin{array}{c}\varepsilon_{v} \\
(\mathrm{~mm} / \mathrm{mm})\end{array}$ \\
\hline & 4 & 0.02 & 30.82 & 16.06 & 2.28 & 1.72 & -0.00205 & 0.00462 & 0.00053 \\
& 4 & 0.05 & 29.15 & 12.54 & 0.62 & 3.38 & -0.00165 & 0.00394 & 0.00064 \\
& 4 & 0.08 & 26.20 & 13.17 & 0.60 & 3.40 & -0.00121 & 0.00372 & 0.00130 \\
& 7 & 0.02 & 36.15 & 20.46 & 4.35 & 2.65 & -0.00262 & 0.00570 & -0.00034 \\
Coal & 7 & 0.05 & 34.99 & 19.72 & 3.80 & 3.20 & -0.00173 & 0.00439 & 0.00093 \\
& 7 & 0.08 & 35.20 & 15.60 & 1.61 & 5.39 & -0.00143 & 0.00395 & 0.00060 \\
& 10 & 0.02 & 50.54 & 24.34 & 6.07 & 3.93 & -0.00285 & 0.00687 & 0.00116 \\
& 10 & 0.05 & 48.75 & 15.68 & 4.53 & 5.47 & -0.00268 & 0.00610 & 0.00074 \\
& 10 & 0.08 & 43.15 & 17.49 & 4.53 & 5.47 & -0.00228 & 0.00562 & 0.00107 \\
& 10 & 0.11 & 44.10 & 11.33 & 1.55 & 8.45 & -0.00211 & 0.00525 & -0.00134 \\
& 10 & 0.14 & 42.24 & 8.45 & 1.39 & 8.61 & -0.00205 & 0.00514 & 0.00025 \\
\hline
\end{tabular}

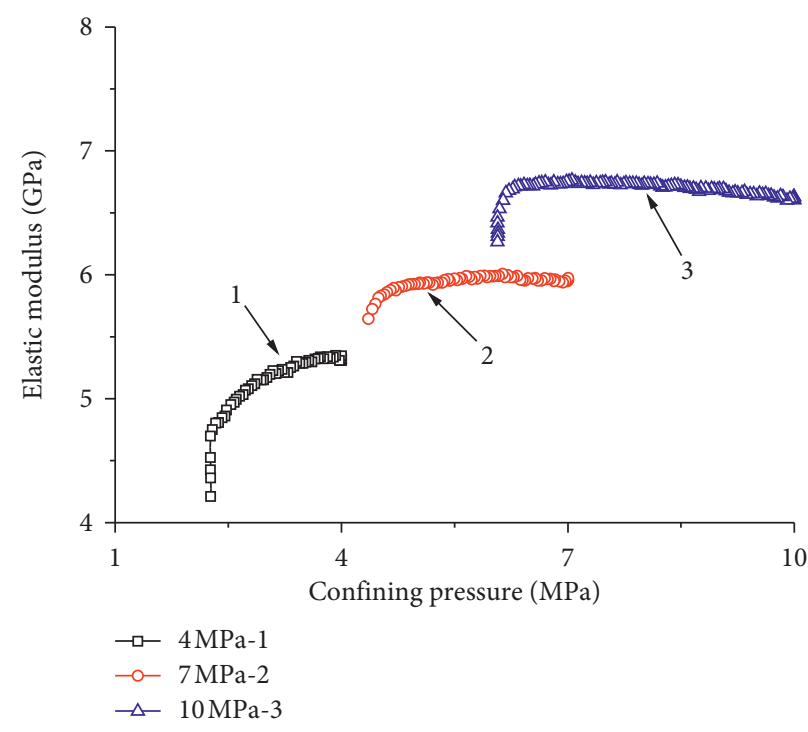

(a)

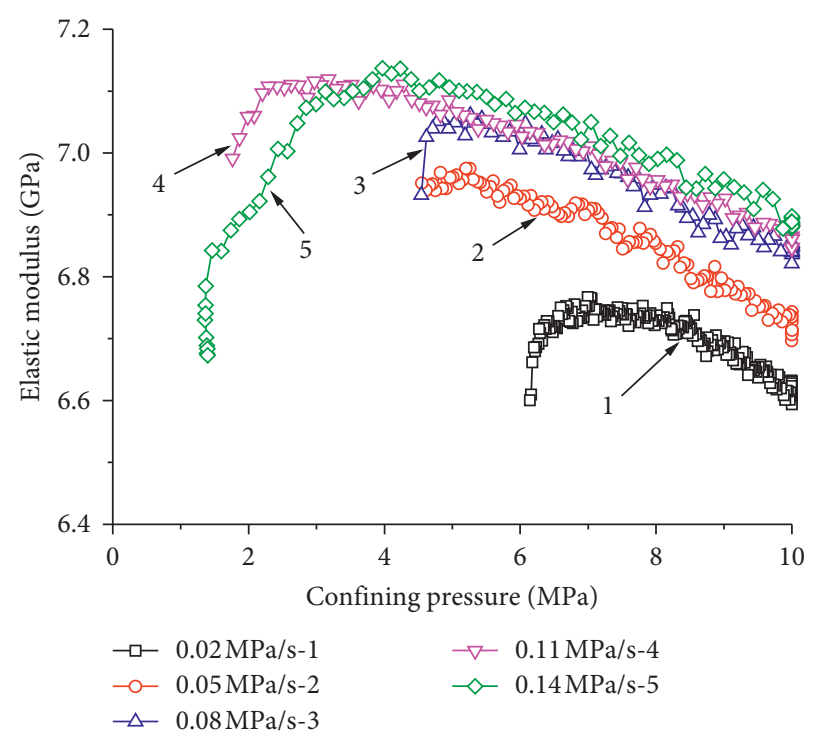

(b)

Figure 5: Elastic modulus under different test conditions. (a) Different confining pressures. (b) Different confining pressure unloading rates.

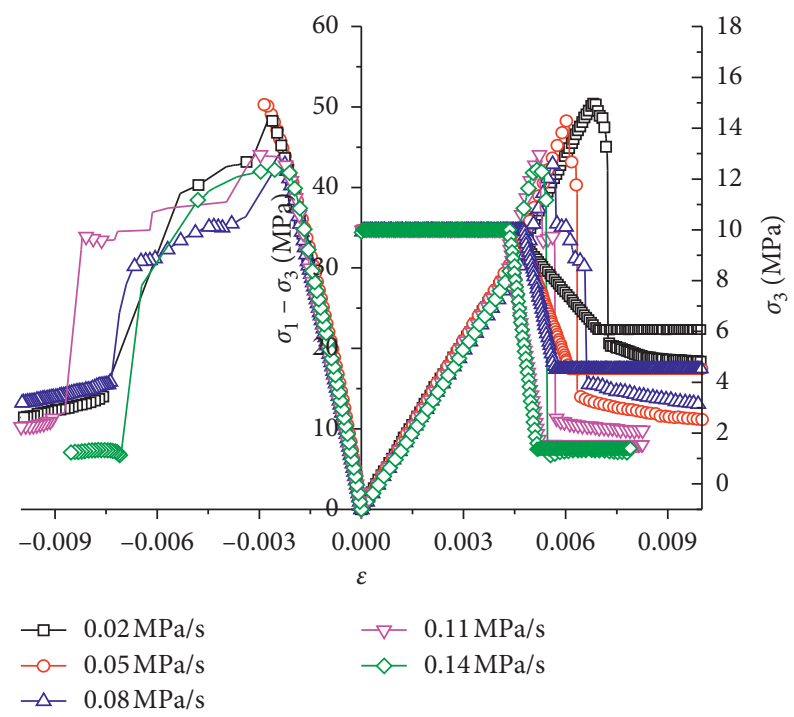

Figure 6: Stress-strain curve of coal samples under different confining pressure unloading rates. difference between the initial and failure confining pressures, $\sigma_{3}-\sigma_{3}^{\prime}$ ) gradually increases. Higher unloading rates are therefore associated with lower confining pressure and the sample is closer to uniaxial compression failure. Higher rates of confining pressure relief are associated with shorter durations of the confining pressure relief period. The above analysis also shows that with increasing confining pressure unloading rate, the failure difficulty decreases gradually.

4.4. Effect of Initial Confining Pressure on Unloading. The stress-strain curves of different coal samples under a range of initial confining pressures are shown in Figure 8. The confining pressure is 4,7 , and $10 \mathrm{MPa}$ and the confining pressure unloading rate is $0.05 \mathrm{MPa} / \mathrm{s}$.

Figure 8 shows that the slope of the stress-strain curves is sensitive to confining pressures when samples are in the elastic deformation stage. This shows that the elastic modulus increases with increasing initial confining pressure during the axial loading stage. 


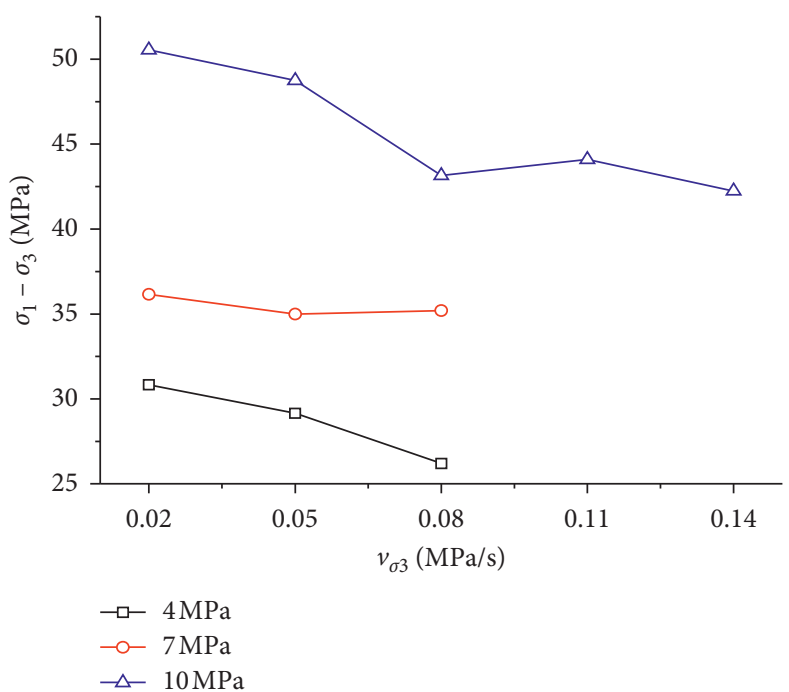

(a)

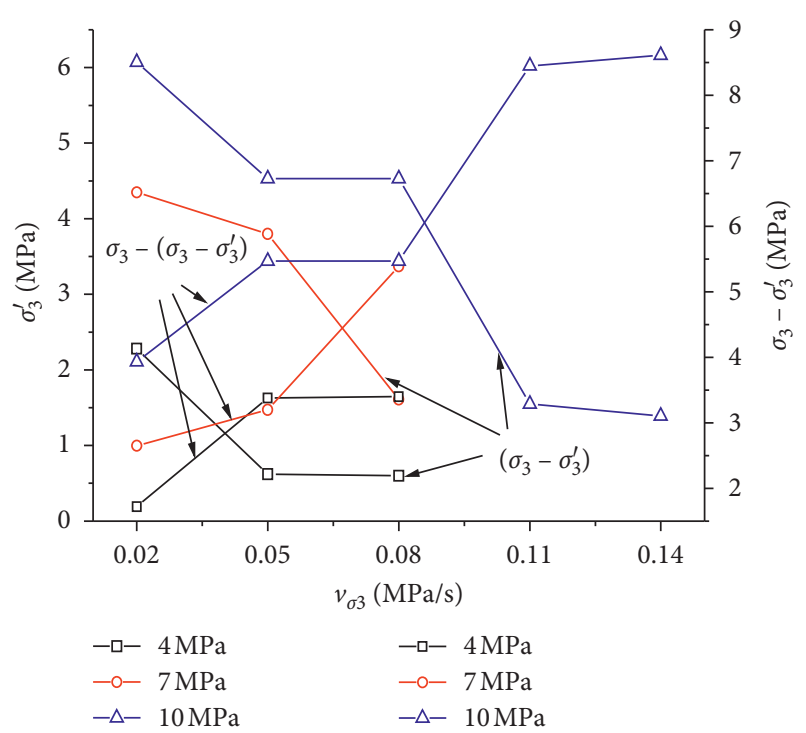

(b)

FiguRe 7: Coal samples under different rates of confining pressure unloading. (a) Major stress difference. (b) Confining pressure and confining pressure difference during failure.

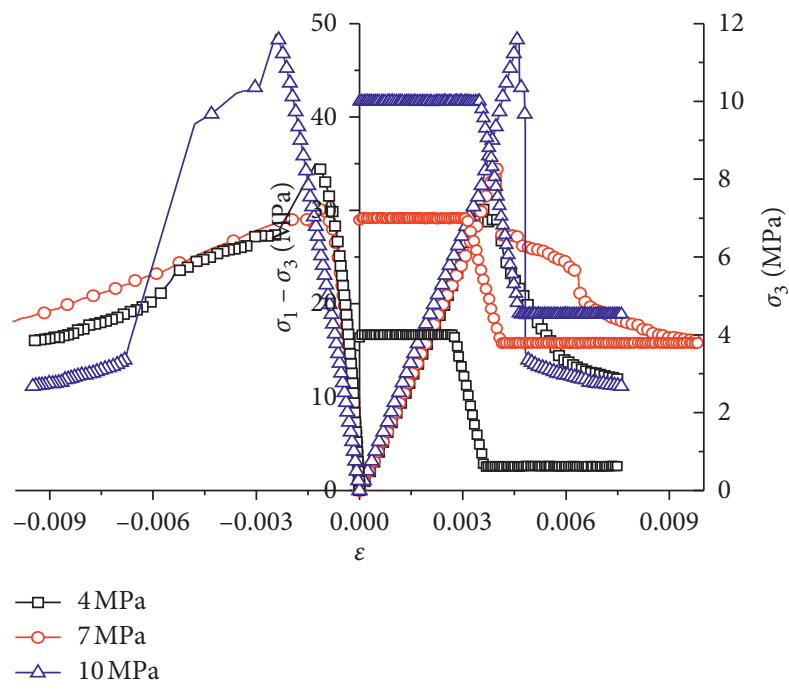

FIGURE 8: Stress-strain curve of coal samples under different confining pressure unloading rates.

The peak principal stress difference increases gradually with increasing initial confining pressure. Higher confining pressures are associated with a greater range of peak principal stress difference as well as a gradual increase in the difference of confining pressure $\left(\sigma_{3}-\sigma_{3}^{\prime}\right)$ between the initial and failure confining pressures, as shown in Figure 9.

\section{Strength Parameter Analysis under Confining Pressure Unloading}

According to the Mohr-Coulomb (M-C) criterion, the internal friction angle and cohesion of coal under conventional triaxial and triaxial confinement unloading tests are calculated by the $\sigma_{1}-\sigma_{3}$ analysis method.
The relationship between the $\mathrm{M}-\mathrm{C}$ strength criterion expressed by $\sigma_{3}$ as an independent variable and $\sigma_{1}$ as dependent variable is as follows:

$$
\sigma_{1}=a+b \sigma_{3},
$$

where $a$ and $b$ are strength-dependent constants. The relationship between $a, b, c$, and $\varphi$ is as follows:

$$
\left.\begin{array}{l}
\sin \varphi=\frac{(b-1)}{(b+1)}, \\
C=\frac{a(1-\sin \varphi)}{2 \cos \varphi} .
\end{array}\right\}
$$

After obtaining a and $b$, these variables are introduced into (2) and $c$ and $\varphi$ are obtained. The results are shown in Table 3.

The data in Table 3 show that $c$ and $\varphi$ are sensitive to test path. Compared with conventional triaxial compression tests, $c$ of coal decreases and $\varphi$ increases under triaxial unloading tests. In the triaxial unloading test, the rate of unloading also has an apparent influence on $c$ and $\varphi$. With increasing unloading rate, $c$ and $\varphi$ gradually decrease.

\section{Discussion}

The dynamic disturbance of rock mass caused by excavation is a common cause of underground engineering disasters. The existing data show that both coal mining and tunnel excavation will cause stress redistribution of surrounding rock, which is an important factor leading to rock burst, and the excavation method has an important impact on the distribution characteristics of rock mass stress. Under the condition of high in situ stress, a lot of strain energy is stored in the rock mass, which becomes high energy storage rock 


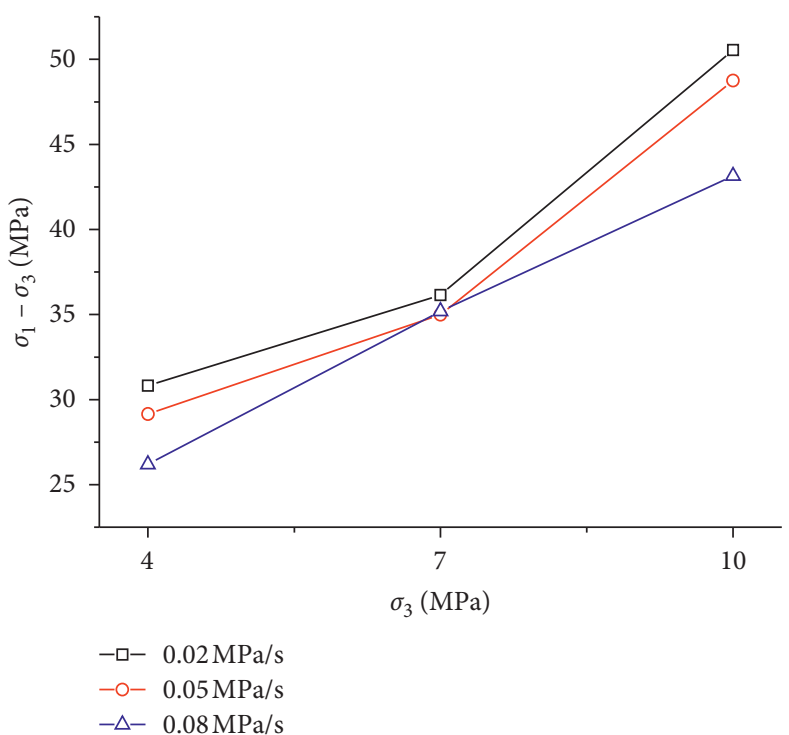

(a)

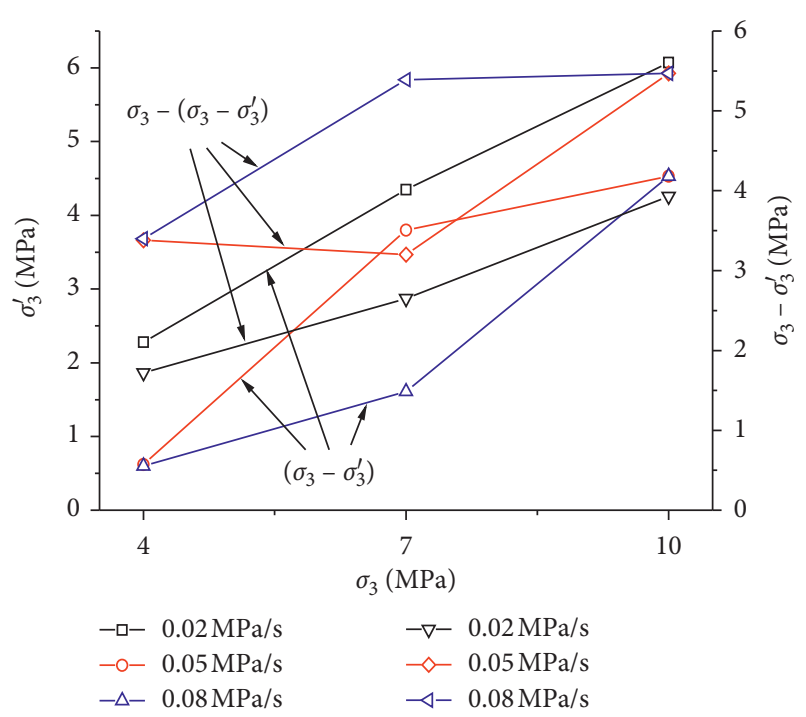

(b)

FIGURE 9: Comparison of samples under different confining pressure unloading rates. (a) Major stress difference. (b) Confining pressure and confining pressure difference during failure.

TABLe 3: Values of $c$ and $\varphi$ of coal samples under different test conditions.

\begin{tabular}{|c|c|c|c|c|c|c|c|c|}
\hline \multirow[t]{2}{*}{ Lithology } & \multirow[t]{2}{*}{ Parameter } & \multirow[t]{2}{*}{ Conventional triaxial } & \multicolumn{3}{|c|}{$\begin{array}{l}\text { Different rates of unloading } \\
\text { confining pressure }(\mathrm{MPa} / \mathrm{s})\end{array}$} & \multicolumn{3}{|c|}{$\begin{array}{l}\text { Ratio of unloading confining } \\
\text { pressure parameters to } \\
\text { conventional triaxial } \\
\text { parameters }\end{array}$} \\
\hline & & & 0.02 & 0.05 & 0.08 & 0.02 & 0.05 & 0.08 \\
\hline Coal & $\begin{array}{c}C(\mathrm{MPa}) \\
\varphi\left(^{\circ}\right)\end{array}$ & $\begin{array}{c}5.47 \\
33.31\end{array}$ & $\begin{array}{c}4.15 \\
35.63\end{array}$ & $\begin{array}{c}3.79 \\
35.50\end{array}$ & $\begin{array}{c}3.77 \\
33.56\end{array}$ & $\begin{array}{l}0.76 \\
1.07\end{array}$ & $\begin{array}{l}0.69 \\
1.07\end{array}$ & $\begin{array}{l}0.69 \\
1.01\end{array}$ \\
\hline
\end{tabular}

mass. The excavation process causes the unloading of in situ stress, the change of rock mass state leads to the instantaneous release and dissipation of the strain energy stored in the high energy storage rock mass, and the occurrence environment and physical and mechanical properties of the rock mass deteriorate, forming the excavation damage area. At the same time, it may induce various engineering geological disasters (e.g., rock burst, sudden large deformation, and rock burst), affect the progress of the project, and even threaten the construction personnel safety of equipment.

In this paper, through the unloading test of coal rock under different test conditions, the mechanical characteristics of coal rock unloading failure are analyzed, and the dynamic change law of mechanical parameters in the process of coal rock unloading is obtained, which lays a foundation for the study of deep rock mass impact disaster mechanism.

\section{Conclusions}

According to the experiments and analysis, the following conclusions can be drawn:
(1) In triaxial unloading tests, the brittleness of coal is more apparent than during conventional triaxial compression tests and there is a brittle sound during failure. The coal strength under triaxial unloading is lower than in triaxial compression tests, which indicates that coal is more likely to fracture under unloading.

(2) In the axial loading stage of the confinement unloading tests, the rate of increase of circumferential strain is less than that of axial strain, which is similar to conventional triaxial compression, and the axial strain plays a leading role. During the confining pressure unloading stage, the circumferential strain clearly increases and plays a leading role.

(3) The elastic modulus of the coal samples shows a close linear relationship with confining pressure at the beginning of confining pressure unloading. With decreasing confining pressure, the elastic modulus increases slowly at a slower rate. In the middle and late stages of the confinement unloading tests, an inflection point appears in the elastic modulus curve, which shows a nonlinear relationship with confining 
pressure. With further decrease of confining pressure, the elastic modulus decreases rapidly, the rate of reduction increases, and a sharp decrease is observed near the failure stage.

(4) Higher unloading rates of confining pressure are associated with shorter times between the peak stress position and sample failure. This shows that samples are more easily destroyed under higher unloading rates. With increasing unloading rate, the peak principal stress difference and confining pressure at failure decrease gradually, whereas the confining pressure difference at failure increases gradually.

(5) Compared with conventional triaxial compression tests, the $c$ value of coal decreases and the $\varphi$ value increases under triaxial confinement unloading tests. With increasing unloading rate, $c$ and $\varphi$ decrease gradually.

\section{Data Availability}

The data used to support the findings of this study are available from the corresponding author upon request.

\section{Conflicts of Interest}

The authors declare that they have no conflicts of interest.

\section{Acknowledgments}

This research was funded by the National Key R\&D Program of China (Grant no. 2018YFC0604705) and the National Natural Science Foundation of China (Grant no. 51574156). This research was also partially funded by the Shandong Province Higher Educational Science and Technology Program (Grant no. J18KA195) and the Natural Science Foundation of Shandong Province (Grant no. ZR2019PD016).

\section{References}

[1] Q. Ha, J. Li, Z. Yongxin et al., Nonlinear mechanics of jointed rock massduring unloading, vol. 14, no. 1, pp. 11-27, China Architecture and Building, Beijing, China, 2020, in Chinese.

[2] K. Ohno and M. Ohtsu, "Crack classification in concrete based on acoustic emission," Construction and Building Materials, vol. 24, no. 12, pp. 2339-2346, 2010.

[3] Y. Yongjie and M. A. Depeng, "Experimental research on energy evolution properties of coal sample failure under triaxial unloading testing," Journal of Mining \& Safety Engineering, vol. 35, no. 6, pp. 1208-1216, 2018, in Chinese.

[4] G. Chunyu, X. Jin, H. Peng et al., "Study of mechanical properties of marble under loading and unloading conditions," Chinese Journal of Rock Mechanics and Engineering, vol. 24, no. 3, pp. 456-460, 2005, in Chinese.

[5] Qiu S., Study on deformation and failure mechanism of deepburied hard rock under loading and unloading conditions and rockburst vulnerability assessment methods, Ph.D. thesis, Wuhan: Institute of Rock and Soil Mechanics. Chinese Academy of Sciences, Wuhan, China, 2011, in Chinese.

[6] B. Wang, Z. Jiebing, W. Aiqing et al., "Experimental study of mechanical properties of Jinping marble under loading and unloading stress paths," Chinese Journal of Rock Mechanics and Engineering, vol. 27, no. 10, pp. 2138-2145, 2008, in Chinese.

[7] S. Song, X. Liu, Y. Tan, D. Fan, Q. Ma, and H. Wang, "Study on failure modes and energy evolution of coal-rock combination under cyclic loading," Shock and Vibration, vol. 2020, Article ID 5731721, 16 pages, 2020.

[8] M. Biancolini, C. Brutti, G. Paparo, and A. Zanini, "Fatigue cracks nucleation on steel, acoustic emission and fractal analysis," International Journal of Fatigue, vol. 28, no. 12, pp. 1820-1825, 2006.

[9] J.-p. Liu, Y.-h. Li, S.-d. Xu, S. Xu, C.-y. Jin, and Z.-s. Liu, "Moment tensor analysis of acoustic emission for cracking mechanisms in rock with a pre-cut circular hole under uniaxial compression," Engineering Fracture Mechanics, vol. 135, pp. 206-218, 2015.

[10] Q. Shili, F. Xiating, Z. Chuanqing et al., "Experimental research on unloading mechanical properties of deep marble under pressures," Chinese Journal of Rock Mechanics and Engineering, vol. 29, no. 8, pp. 1807-1817, 2010, in Chinese.

[11] D. Ma, Y. Zhou, and Ch.X. Liu, "Creep behavior and acoustic emission characteristics of coal samples with different moisture content," Acta Geodynamica et Geomaterialia, vol. 15, no. 4, pp. 405-412, 2018.

[12] R. Huang and D. Huang, "Experimental research on affection laws of unloading rates on mechanical properties of Jinping marble under high geostress," Chinese Journal of Rock Mechanics and Engineering, vol. 29, no. 1, pp. 21-33, 2010, in Chinese.

[13] G. Wu and J. Sun, "Deformation and strength characters of jointed rock mass under unloading stress states," Chinese Journal of Rock Mechanics and Engineering, vol. 17, no. 6, pp. 615-621, 1998, in Chinese.

[14] D. Fan, X. Liu, Y. Tan et al., "Roof cutting parameters design for gob-side entry in deep coal mine: a case study," Energies, vol. 12, no. 10, p. 2032, 2019.

[15] Y. L. Tan, X. S. Liu, B. Shen, Q. H. Gu, and J. G. Ning, "New approaches to testing and evaluating the rockburst risk of coal seam with hard roof and/or floor in coal mines," Geomechanics and Engineering, vol. 14, no. 4, pp. 367-376, 2018.

[16] L. Hongzhe, X. Caichu, Y. Zijian et al., "Study of marble unloading mechanical properties of Jinping hydropower station under high geostress conditions," Chinese Journal of Rock Mechanics and Engineering, vol. 26, no. 10, pp. 21042109, 2007, in Chinese.

[17] K. Zhang, H. Zhou, P. Pengzhi, and L. Shen, "Characteristics of strength of rocks under different unloading rates," Rock and Soil Mechanics, vol. 31, no. 7, pp. 2072-2078, 2010, in Chinese.

[18] M. You and H. Anzeng, "Triaxial confining pressure unloading test of rock sample," Chinese Journal of Rock Mechanics and Engineering, vol. 17, no. 1, pp. 24-29, 1998, in Chinese.

[19] C. D. Martin, "Seventeenth Canadian geotechnical colloquium: the effect of cohesion loss and stress path on brittle rock strength," Canadian Geotechnical Journal, vol. 34, no. 5, pp. 698-725, 1997.

[20] M. Cai, P. K. Kaiser, Y. Tasaka, T. Maejima, H. Morioka, and M. Minami, "Generalized crack initiation and crack damage stress thresholds of brittle rock masses near underground excavations," International Journal of Rock Mechanics and Mining Sciences, vol. 41, no. 5, pp. 833-847, 2004.

[21] Y. Yang, Y. Zhou, D. Ma, H. Ji, and Y. Zhang, "Acoustic emission characteristics of coal under different triaxial unloading conditions," Acta Geodynamica et Geomaterialia, vol. 17, no. 1, pp. 51-60, 2020. 
[22] W. T. Li, N. Yang, Y. C. Mei, Y. H. Zhang, L. Wang, and H. Y. Ma, "Experimental investigation of the compressionbending property of the casing joints in a concrete filled steel tubular supporting arch for tunnel engineering," Tunnelling and Underground Space Technology, vol. 96, Article ID 103184, 2020.

[23] W. Chen, L. Senpeng, G. Xiaohong et al., "Research on unloading confining pressure tests and rockburst criterion based on energy theory," Chinese Journal of Rock Mechanics and Engineering, vol. 28, no. 8, pp. 1530-1540, 2009, in Chinese.

[24] Hu Y.. Study on mechanical properties of granites under high stress conditions and its constitutive models, Ph.D. thesis. Wuhan: Institute of Rock and Soil Mechanics, Chinese Academy of Sciences, Wuhan, China, 2008, in Chinese.

[25] L. Zhijing, Z. Zhende, S. Yi et al., "Unloading strength properties of rocks under high confining pressure and hydraulic pressure," Journal of Hohai University: Natural Sciences, vol. 37, no. 2, pp. 162-165, 2009, in Chinese.

[26] S. Chen, D. Yin, N. Jiang, F. Wang, and Z. Zhao, "Mechanical properties of oil shale-coal composite samples," International Journal of Rock Mechanics and Mining Sciences, vol. 123, Article ID 104120, 2019. 